\title{
Cholesterol, phospholipid and phospholipase activity of ampullary and isthmic fluid from the bovine oviduct
}

\author{
A. A. Grippo, S. H. Anderson, D. A. Chapman, M. A. Henault and \\ G. J. Killian*
}

Dairy Breeding Research Center, Department of Dairy and Animal Science, The Pennsylvania State University, University Park, PA 16802, USA

\begin{abstract}
Cholesterol and phospholipid concentrations and phospholipase activity were measured in fluid from cannulae collected from the bovine oviductal isthmus and ampulla at different stages of the oestrous cycle. The cholesterol concentration and cholesterol normalized by protein were significantly $(P=0.03)$ greater in isthmic oviductal fluid $\left(224.3 \pm 42.7 \mu \mathrm{g} \mathrm{ml}^{-1}\right.$ over all stages) than in ampullary oviductal fluid (164.5 $\pm 11.3 \mu \mathrm{g} \mathrm{ml}^{-1}$ ), and maximal concentrations $\left(284.5 \pm 25.5 \mu \mathrm{g} \mathrm{ml}^{-1}\right)$ were found during the luteal stage (serum progesterone concentration $\geqslant 1.5 \mathrm{ng} \mathrm{ml}^{-1}$ ). The concentrations of the phospholipids sphingomyelin and lysophosphatidylcholine increased at different stages of the cycle and in different regions. In the ampulla, the concentration of sphingomyelin was significantly $(P<0.05)$ greater in oviductal fluid collected during the luteal phase $(12.1 \pm 2.7 \%$ of total phospholipids) than in fluid collected near oestrus and ovulation $(7.5 \pm 1.5 \%$ and $6.9 \pm 1 \%$, respectively). The concentration of lysophosphatidylcholine was greater $(P<0.01)$ in ampullary (19.2 $\pm 1.6 \%$ of total phospholipids) than in isthmic oviductal fluid $(9.9 \pm 1.1 \%)$ collected near ovulation. The ratio of cholesterol to total phospholipid was highest in oviductal fluid collected from the isthmus during all stages $\left(2.3 \mu \mathrm{g} \mathrm{ml}^{-1}: \%\right.$ total phospholipid), while the minimal ratio was found in ampullary fluid collected near ovulation (1.5). Phospholipase activity was higher $(P=0.03)$ in isthmic oviductal fluid $(20.4 \pm 3.2 \%$ product

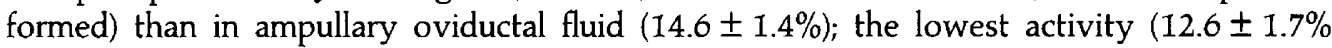
product formed) was in fluid collected during the phase of the oestrous cycle immediately before ovulation. We conclude that the regional and temporal differences in the concentrations of lipids in oviductal fluid provide general support for the concept that the isthmus serves as a sperm reservoir, while the ampulla is the site of the bovine sperm acrosome reaction.
\end{abstract}

\section{Introduction}

Cholesterol and phospholipids are known to affect membrane stability and appear to influence the fertilizing potential of spermatozoa. The addition of exogenous cholesterol decreases sperm fertility in rats and guinea-pigs (Davis, 1976; Fleming and Yanagimachi, 1981). Diaz-Fontdevila and Bustos-Obregon (1993) reported that hypercholesterolaemia and hypertriglyceridaemia in male rabbits decrease the capacity of spermatozoa to undergo the acrosome reaction. Desmosterol decreases hamster sperm capacitation (Bleau et al., 1975) and cholesterol3-sulfate reduces the fertility of capacitated rabbit spermatozoa (Fayrer-Hosken $e$ al., 1987). These sterols may affect fertility by becoming incorporated into sperm membranes and promoting membrane stability (Davis, 1976; Ehrenwald et al., 1988).

Conversely, exogenous phospholipids apparently have a destabilizing effect on sperm membranes. A decrease in the

*Correspondence.

Received 28 January 1994. cholesterol:phospholipid ratio in the sperm plasma membrane may facilitate capacitation and the acrosome reaction in mammals (Davis et al., 1979). Exogenous phospholipids, especially phosphatidylcholine, are associated with bull spermatozoa (Evans and Setchell, 1978) and dilauroylphosphatidylcholine induces the acrosome reaction in hamster spermatozoa (Graham and Foote, 1987a, b). Lysophosphatidylcholine and other lysophospholipids affect the acrosome reaction in guineapig spermatozoa (Fleming and Yanagimachi, 1981) and induction of capacitation and the acrosome reaction in bull spermatozoa (Wheeler and Seidel, 1989).

Phospholipids are produced from triacylglycerols by the activity of phospholipases. Phosphatidylcholine is converted to its lyso form by the enzyme phospholipase $A_{2}$, itself a potent facilitator of the acrosome reaction (Singleton and Killian, 1983). In mammalian spermatozoa, phospholipase $A_{2}$ is present within the sperm cell membrane (Ohzu and Yanagimachi, 1982; Thakkar et al., 1984), and membrane destabilization due to activity of this enzyme is implicated in capacitation and the acrosome reaction (Langlais and Roberts, 1985). In addition, the 
lysophospholipid products of phospholipase $A_{2}$ accelerate destabilization and the rate of the acrosome reaction in the presence of $\mathrm{Ca}^{2+}$ (Fleming and Yanagimachi, 1981, 1984; Yanagimachi and Suzuki, 1985).

Fluid in the oviductal lumen provides the microenvironment for gametes before fertilization. The molecular components of this fluid are probably crucial to the biochemical preparation of spermatozoa for fertilization. We have studied the composition of cannula-derived oviductal fluid produced during the luteal and nonluteal phases of the oestrous cycle, and found that the concentrations of cholesterol are lower and those of phospholipids generally higher during the nonluteal phase (Killian et al., 1989). These conditions favour the occurrence of capacitation and the acrosome reaction.

Several studies have suggested specific regional functions of the oviduct in preparing spermatozoa for fertilization (Hunter and Wilmut, 1984). The present study was undertaken to define the amounts of cholesterol and phospholipids, and phospholipase activity in fluid from isthmic and ampullary regions of the oviduct during the oestrous cycle. The results give a better definition of the potential role of these important molecules in preparing spermatozoa for fertilization.

\section{Materials and Methods}

\section{Collection and storage of bovine oviductal fluid}

Laparotomies on cows ( $n=4$ or 5 ) in the standing position were performed to cannulate oviducts, as described in detail by Kavanaugh et al. (1991); the side of ovulation was not noted. Each oviduct contained ampullary and isthmic catheters that were exteriorized through flank incisions to sterile collection vials. The vials were retained in a canvas pouch mounted with adhesive to the flank. Animals were allowed to recover from surgery for at least 1 week before oviductal fluid was taken. Receptacles containing oviductal fluid were replaced daily. After measuring volume and osmolality, oviductal fluid was frozen and stored in liquid nitrogen until analysis. Aseptic technique was used in handling all oviductal fluid samples, and fluid was examined at the time of thaw for obvious signs of contamination.

Daily serum progesterone concentrations were determined to define the stages of the oestrous cycle (Killian et al, 1989). The luteal phase of the cycle included all days when serum progesterone concentrations were $\geqslant 1.5 \mathrm{ng} \mathrm{ml}^{-1}$, and the nonluteal phase was defined by serum progesterone concentrations $<1.5 \mathrm{ng} \mathrm{ml}^{-1}$. Oestrus was assumed to be 4 days before the initial rise in progesterone, following the period when progesterone concentrations were $<1.5 \mathrm{ng} \mathrm{ml}^{-\frac{1}{2}}$. The nonluteal phase was subdivided into two phases: nonluteal 1 phase, which was the $2-5$ days before the day of oestrus when serum progesterone concentrations were $<1.5 \mathrm{ng} \mathrm{ml}^{-1}$; and nonluteal 2 phase, comprising the 4 days before the initial rise in progesterone and which included oestrus and ovulation.

\section{Determination of protein, cholesterol and phospholipid concentrations}

Samples of oviductal fluid were assessed for protein concentration (Lowry et al., 1951) using BSA as a standard.
Cholesterol concentrations were determined using a diagnostic kit (No. 351, Sigma Chemical Co., St Louis, MO). Extraction of phospholipids (Folch et al., 1957) from oviductal fluid was accomplished using chloroform:methanol $(2: 1, \mathrm{v}: \mathrm{v})$, and $\mathrm{KCl}$ solution $(0.74 \%)$ in the washing step to maximize phospholipid recovery to $92 \%$ (Killian et al., 1989).

Phospholipids were separated by HPLC, composed of injector (Model U6K, Waters Chromatography, Milford, MA), pump (Model 510, Waters Chromatography) and an Econosphere Silica $5 \mathrm{u}$ cartridge column $(4.6 \mathrm{~mm} \times 15 \mathrm{~cm}$; Alltech Associates, Inc., Deerfield, IL) placed in series with a Supercosil LC-Si column $(4.6 \mathrm{~mm} \times 5 \mathrm{~cm}$; Supelco, Inc., Bellefonte, PA). The mobile phase was an isocratic solvent system of acetonitrile:methanol:water $(65: 21: 14, \quad \mathrm{v}: \mathrm{v}: \mathrm{v})$. The effluent was monitored at $207 \mathrm{~nm}$ with a Waters Lambda-Max Model $481 \mathrm{LC}$ spectrophotometer at a constant flow rate of $1 \mathrm{ml} \mathrm{min}{ }^{-1}$. Data were exported to a computer and analysed by an HPLC PEKPKR software program (Centre Computer Consultants, State College, PA). Effluent fractions ( $1 \mathrm{ml}$ ) were dried in air, subjected to complete perchloric acid digestion and analysed for inorganic phosphorus (Killian and Chapman, 1980). Unknown compounds were identified by comparison with elution times of phosphatidylserine (PS), lysophosphatidylserine (LPS), phosphatidylethanolamine (PE), lysophosphatidylethanolamine (LPE), phosphatidylcholine (PC), lysophosphatidylcholine (LPC), phosphatidylinositol (PI), cardiolipin (CL) and sphingomyelin (SM) standards (Sigma Chemical Co.). The elution profiles of PE and LPE were essentially identical, so PE and LPE were analysed as a pair.

\section{Phospholipase activity}

A fluorescent phospholipase substrate, 3-palmitoyl-2(1-pyrendecanolyl)-I-phosphatidylcholine (PPC; Molecular Probes, Inc., Eugene, OR) was dissolved in $1 \mathrm{mg}$ ethanol $\mathrm{ml}^{-1}$ and $10 \mu \mathrm{l}$ was combined with $200 \mu \mathrm{l}$ oviductal fluid. After thorough mixing and incubation at $37^{\circ} \mathrm{C}$ for $30 \mathrm{~min}$, lipids were extracted by the Folch method. After centrifugation $(750 \mathrm{~g}, 30 \mathrm{~min}$ ), aliquots were removed from the bottom layer, and stored in liquid nitrogen if not analysed immediately. Samples were dried under a stream of nitrogen gas dissolved in ethanol and separated by HPLC as described below to quantify the fluorescent product, 6-pyrenyldecanoic acid (PDA).

The assay for phospholipase activity was developed and validated in our laboratory. The HPLC system was fitted with a Hibar II LiChrosorb Si60 column $(4.6 \mathrm{~mm} \times 25 \mathrm{~cm}$; Rainin Instrument Co., Woburn, MA) in series with a Supelcosil LC-Si column $(4.6 \mathrm{~mm} \times 5 \mathrm{~cm}$; Supelco, Inc.), and a Turner fluorometer (Model 112). The fluorometer contained a 7-60 primary filter (excitation peak at $350-375 \mathrm{~nm}$ ) and a 2 A secondary filter (emission at $420-450 \mathrm{~nm}$ ). Separations were achieved by the same isocratic solvent system used for phospholipid analysis. Activity of phospholipase on PPC yielded the fluorescent compound PDA, which was compared with a standard (Molecular Probes, Inc.). At a flow rate of $1 \mathrm{ml} \mathrm{min}{ }^{-1}$, the PDA product peak eluted at $2 \mathrm{~min}$ and the PPC substrate peak eluted at 6 min.

For assay validation, isolated porcine pancreatic phospholipase $A_{2}$ (No. P6534, Sigma Chemical Co.) was diluted to 


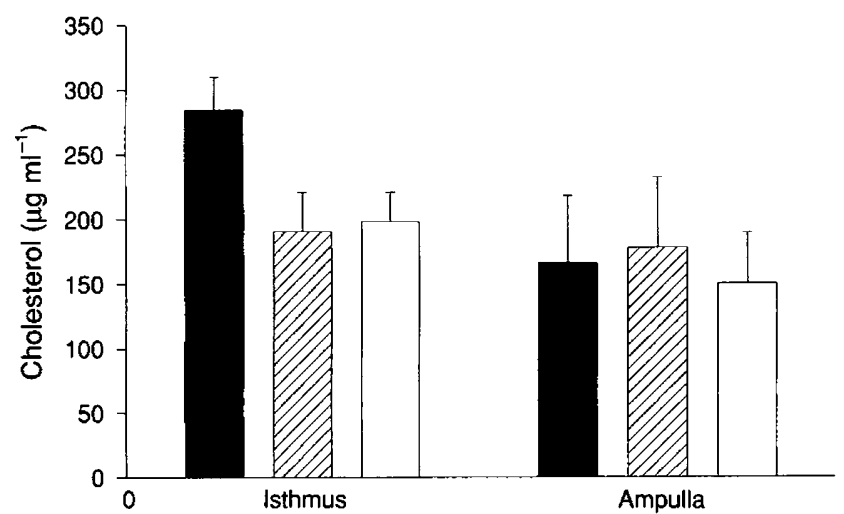

Fig. 1. Concentration of cholesterol $\left(\mu \mathrm{g} \mathrm{ml}{ }^{-1}\right)$ in bovine oviductal fluid $(n=5$; mean $\pm \mathrm{SD}$ ) collected from isthmus and ampulla during luteal $(\square)$, nonluteal $1(\square)$ and nonluteal $2(\square)$ stages of the oestrous cycle. Statistically significant differences are indicated in Table 1.

$0.011 \mathrm{mg} \mathrm{ml}^{-1}$ in Hepes-buffered saline (HBS; $0.238 \mathrm{~g}$ Hepes, $0.877 \mathrm{~g} \mathrm{NaCl}$ in $100 \mathrm{ml}, \mathrm{pH} 7.2$ ), and added to reaction tubes containing PPC and HBS to give a final volume of $210 \mu \mathrm{l}$. Samples were shaken and incubated at $37^{\circ} \mathrm{C}$ for $30 \mathrm{~min}$. Standard curves were obtained by extracting either PPC or PDA by vortexing the substrate or product with buffer and incubating at $37^{\circ} \mathrm{C}$ for $30 \mathrm{~min}$. After centrifugation $(750 \mathrm{~g}$ for $30 \mathrm{~min}$ ) at $25^{\circ} \mathrm{C}$, an aliquot of $\mathrm{I} \mathrm{ml}$ was removed from the bottom layer of each sample, dried under nitrogen gas, and dissolved in $50 \mu \mathrm{l}$ pure ethanol. A $25 \mu \mathrm{l}$ aliquot of this solution was injected into the HPLC.

\section{Statistical analyses of regional oviductal fluid assay}

The effects of cow ( $n=5$, cholesterol; $n=4$, phospholipid; $n=5$, phospholipase), stage of the oestrous cycle and region of the oviduct on either percentage phospholipid or phospholipase activity in oviductal fluid were determined using general linear models (GLM) analysis of variance (SAS, 1985). The stage was luteal, nonluteal 1 or nonluteal 2; region was either isthmic or ampullary oviductal fluid. For phospholipids (PS, LPS, PE/LPE, PC, LPC, PI, CL, SM, UNK) the model was $Y=$ cow stage region stage*region. Comparisons were made using the Bonferroni $t$ test of differences between means, with significance accepted at $P \leqslant 0.05$. Variance and normality were analysed to test for violations to the model assumptions. Because the assumptions were adhered to, no transformations of the percentage data were required.

\section{Results}

\section{Cholesterol concentration}

Over all stages of the cycle, the cholesterol concentration was greater in isthmic than in ampullary fluid (Fig. I; see Table 1 for a list of statistically significant differences). This difference between regions approached significance $(P<0.1)$ only in fluid collected during the luteal phase of the oestrous cycle. Considering the stage of the oestrous cycle, the average cholesterol concentration in isthmic oviductal fluid collected during the luteal phase $\left(285 \pm 26 \mu \mathrm{g} \mathrm{ml}^{-1}\right)$ was generally but not significantly higher $(P<0.1)$ than that in isthmic oviductal fluid collected during nonluteal $1\left(191 \pm 31 \mu \mathrm{g} \mathrm{ml}^{-1}\right)$ and nonluteal $2\left(198 \pm 23 \mu \mathrm{g} \mathrm{ml}^{-1}\right)$ stages.

When the cholesterol concentration in oviductal fluid was normalized by protein concentration, both regional and stage effects were significant (Table 1). The highest cholesterol: protein ratio was found in oviductal fluid collected during the luteal phase $\left(27.5 \pm 4.6 \mu \mathrm{g}\right.$ cholesterol $\mathrm{mg}^{-1}$ protein in isthmic fluid; $17.9 \pm 2.5$ in ampullary). The mean cholesterol:protein ratio of luteal oviductal fluid collected from both regions was higher than that collected during any other stage of the oestrous cycle. Oviductal fluid collected during the nonluteal 2 stage from the isthmic region had $16.1 \pm 3.0 \mu \mathrm{g} \mathrm{mg}^{-1}$, and the cholesterol:protein ratio in the ampullary was $15.1 \pm 1.0 \mu \mathrm{g}$ $\mathrm{mg}^{-1}$ protein. The lowest cholesterol:protein concentrations were found in fluid collected during the nonluteal 2 stage, with $13.9 \pm 2.1 \mu \mathrm{g} \mathrm{mg}^{-1}$ protein found in isthmic fluid and $14.6 \pm 2.4 \mu \mathrm{g} \mathrm{mg}^{-1}$ protein found in ampullary fluid. Comparing stage within region, isthmic oviductal fluid collected during the luteal phase had a greater cholesterol:protein ratio than that collected during the nonluteal 1 phase $(P<0.01$; Table 1$)$.

\section{Phospholipid concentration}

No significant interactions with respect to region, stage or region by stage were found for relative amounts of PI or CL measured in bovine oviductal fluid (Fig. 2; Table 1). However, significant regional effects were noted for both PS and LPS in oviductal fluid (Fig. 2; Table 1), with relative amounts of both phospholipids greater in isthmic than in ampullary oviductal fluid.

Significant regional and stage effects were also detected for PC (Fig. 2; Table 1). The mean percentage of PC was greater in ampullary than in isthmic fluid, and the mean amount of $\mathrm{PC}$ during the luteal stage was greater than that during the nonluteal 2 stage.

For LPC, a significant regional effect and a region by stage interaction was detected (Fig. 2; Table 1). The mean percentage of LPC in the total phospholipid concentration in ampullary oviductal fluid was greater than that in isthmic oviductal fluid. In ampullary oviductal fluid, the mean percentage of LPC during the luteal phase was less than that of the nonluteal $I$ or nonluteal 2 phases. Conversely, in isthmic oviductal fluid, the percentage of LPC found in luteal fluid was greater than that in nonluteal 1 or nonluteal 2 oviductal fluid. In oviductal fluid collected during the nonluteal 2 stage, the percentage of LPC was greater in ampullary than in isthmic oviductal fluid.

A significant effect of stage was noted for the percentage of SM in the total phospholipid concentration; SM was greater in oviductal fluid collected during the luteal than during the nonluteal 2 phase (Fig. 2; Table 1). In the ampulla, the mean percentage of SM in oviductal fluid in the luteal phase was greater than that found in fluid from both nonluteal $I$ and nonluteal 2 phases.

The percentage of unknown phospholipids differed significantly according to region (Fig. 2; Table 1). The mean percentage of unknown phospholipid, as a percentage of the total phospholipid concentration, was greater in isthmic than in ampullary fluid. 
Table 1. Summary of statistically significant differences observed between regional and temporal sources of cholesterol, cholesterol:protein, phospholipids and phospholipase activity in bovine oviductal fluid

\begin{tabular}{|c|c|c|c|}
\hline Lipid & Region & Stage & Region $\times$ stage \\
\hline Cholesterol $(n=5)$ & $\mathrm{I}>\mathrm{A} ; P=0.03$ & NS & NS \\
\hline Cholesterol:protein $(n=5)$ & $\mathrm{I}>\mathrm{A} ; P=0.05$ & $\begin{array}{c}\mathrm{L}>\mathrm{NL} 1, \mathrm{NL} 2 ; P<0.01 \\
\mathrm{~L}>\mathrm{NL} 2 ; P=0.02\end{array}$ & $\begin{array}{c}\mathrm{NS} \\
\mathrm{I}: \mathrm{L}>\mathrm{NLI} ; P<0.01\end{array}$ \\
\hline \multicolumn{4}{|l|}{ Phospholipids (\% of total) $(n=4)$} \\
\hline Phosphatidylserine & $\mathrm{I}>\mathrm{A} ; \mathrm{P}=0.01$ & NS & NS \\
\hline Lysophosphatidylserine & $\mathrm{I}>\mathrm{A} ; P<0.05$ & NS & NS \\
\hline $\begin{array}{l}\text { Phosphatidylethanolamine/ } \\
\text { lysophosphatidylethanolamine }\end{array}$ & $A>I ; P<0.05$ & NLI $>$ NL; $P=0.03$ & NS \\
\hline Phosphatidylcholine & A $>$ I $P=0.05$ & $\mathrm{~L}>\mathrm{NL} 2 ; P=0.02$ & NS \\
\hline Lysophosphatidylcholine & A $>$ I $P<0.01$ & NS & $\begin{array}{l}\text { ANL2 }>\text { INL2; } P=0.001 \\
\text { l: } \mathrm{L}>\mathrm{NL} 1 ; P<0.02 \\
\mathrm{l}: \mathrm{L}>\mathrm{NL} 2 ; P<0.02 \\
\text { A: NL1 }>\text { L; } P<0.02 \\
\quad \text { A: NL2 }>\text { L; } P<0.001\end{array}$ \\
\hline Sphingomyelin & NS & $\mathrm{L}>\mathrm{NL2} ; P<0.01$ & $\begin{array}{l}\text { A: } L>N \text { NLI } P<0.05 \\
\quad \text { A: } L>N L 2 ; P<0.02\end{array}$ \\
\hline Unidentified & $\mathrm{I}>\mathrm{A}_{i} P=0.03$ & NS & NS \\
\hline Phospholipase activity $(n=5)$ & $\mathrm{I}>\mathrm{A}_{;} P=0.03$ & $\begin{array}{l}\mathrm{L}>\mathrm{NL} 1 ; P=0.05 \\
\quad \mathrm{NL} 2>\mathrm{NL} 1 ; P=0.05\end{array}$ & $\begin{array}{l}\text { INL2 }>\text { ANL2: } P<0.01 \\
\text { I: NL2 }>\text { NL1; } P<0.01\end{array}$ \\
\hline
\end{tabular}

A: ampulla; I: isthmus; L: luteal; NL1: nonluteal 1; NL2: nonluteal 2; NS: not significant.

\section{Cholesterol:phospholipid ratios}

The ratio of cholesterol concentration:total phospholipid concentration was higher in isthmic than in ampullary oviductal fluid collected during all stages of the oestrous cycle (Fig. 3a). The lowest cholesterol:phospholipid ratio was determined in ampullary oviductal fluid during the nonluteal 2 stage. A similar pattern was observed when cholesterol was compared with the total lysophospholipid concentration (data not shown), and the ratio of cholesterol:LPC alone was also lowest in oviductal fluid collected from the ampulla during both nonluteal stages (Fig. 3b).

\section{Phospholipase activity in oviductal fluid}

Significant regional and stage effects of phospholipase activity in oviductal fluid were detected (Fig. 4; Table 1). The mean phospholipase activity in isthmic oviductal fluid was higher than in ampullary fluid. The mean activity of phospholipase in oviductal fluid collected during the nonluteal $I$ phase was lower than that collected during either the luteal or nonluteal 2 phases.

In isthmic oviductal fluid, the mean phospholipase activity during the nonluteal 2 phase was greater than that of the nonluteal 1 phase, and was greater than that in ampullary nonluteal 2 oviductal fluid.

The HPLC assay yielded replicable, linear standard curves relating known amounts of extracted phospholipase product (PDA) or substrate (PPC) versus area under the peak from 0 to $2.68 \times 10^{2} \mu \mathrm{mol}$ (Grippo et al., 1989). The HPLC assay was compared with two previously reported assays (Consentino and Ellis, 1981; Thuren et al., 1985) by incubating identical concentrations of substrate with identical concentrations of phospholipase for several time points ranging from 0 to 120 min (data not shown). All assays demonstrated similar phospholipase activity curves for $0-60 \mathrm{~min}$. Similar results were also obtained when the concentration of substrate was held constant and concentrations of enzyme were varied (Grippo et al., 1989).

\section{Discussion}

The results of the present study demonstrate regional and cyclic distinctions in bovine oviductal fluid. Oviductal fluid from the isthmus has a high cholesterol concentration and a generally lower phospholipid content, resulting in higher cholesterol:phospholipid ratios than in ampullary oviductal fluid. These properties provide a stabilizing environment for membranes of spermatozoa that pass through or reside in the isthmus.

Cholesterol concentrations in the gamete environment apparently play a role in the stability of sperm membranes. An increase in cholesterol in the incubation medium decreases acrosome reactions in rat and guinea-pig spermatozoa (Langlais et al., 1988). We have found that mean cholesterol concentrations are higher in isthmic oviductal fluid than in ampullary fluid and the highest concentrations were found in isthmic fluid during the luteal stage.

These results parallel previous studies on lipid synthesis by bovine oviduct explants (Henault and Killian, 1993a). Although these authors found that a wide variety of lipids was rapidly synthesized from $\left[{ }^{14} \mathrm{C}\right]$ acetate, cholesterol was the predominant synthesized lipid released into the culture supernatant by isthmic cells (Henault and Killian, 1993b). Moreover, analysis of lipid droplets recovered from oviductal epithelial cells 


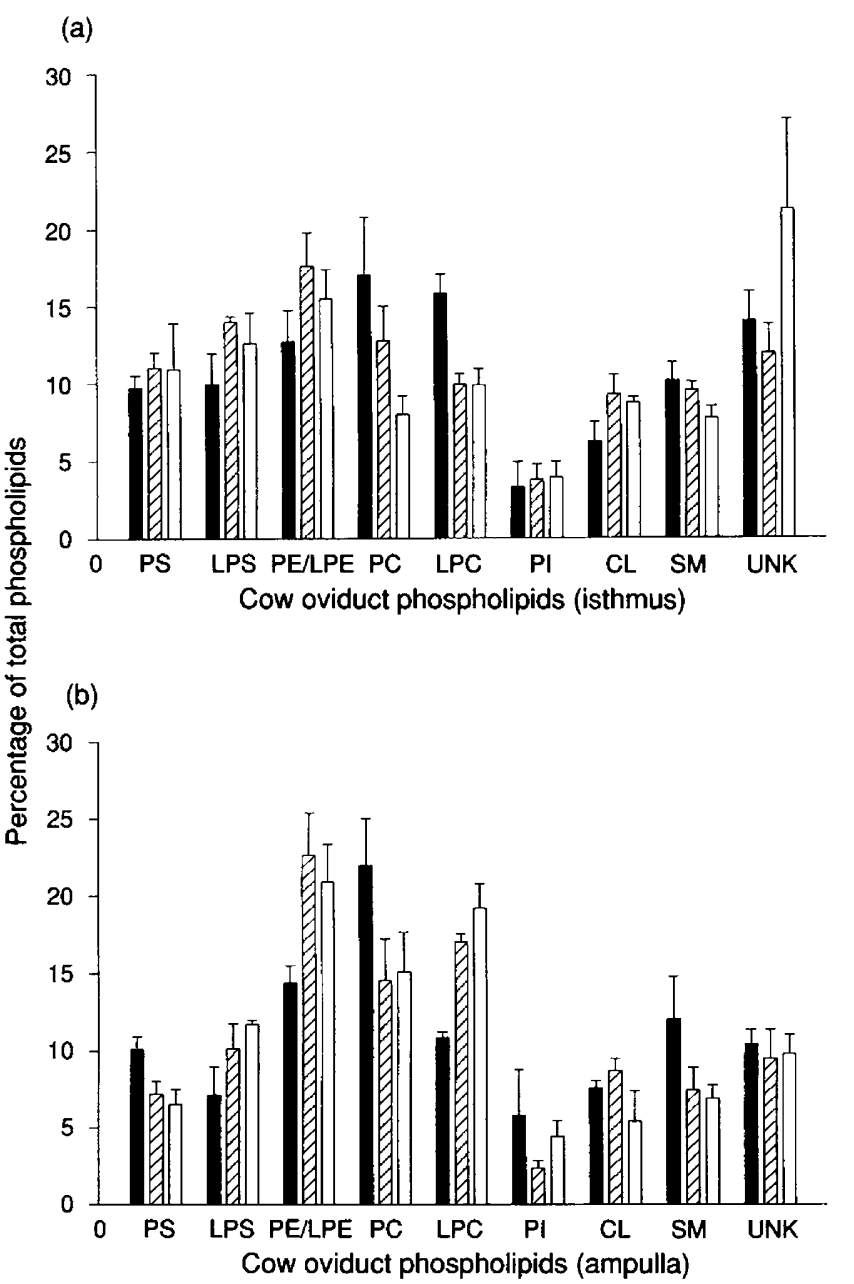

Fig. 2. Phospholipid concentrations (percentage of total phospholipids) in bovine oviductal fluid ( $n=4$; mean \pm SD) collected from (a) the isthmic region and (b) the ampullary region during luteal (a), nonluteal $1(\square)$ and nonluteal $2(\square)$ stages of the oestrous cycle. PS: phosphatidylserine; LPS: lysophosphatidylserine; PE: phosphatidylethanolamine; LPE: lysophosphatidylethanolamine; PC: phosphatidylcholine; LPC: lysophosphatidylcholine; PI: phosphatidylinositol; CL: cardiolipin; SM: sphingomyelin; UNK: unidentified. Statistically significant differences are indicated in Table 1 .

revealed more total lipid in droplets from cows in the luteal phase, mainly due to large amounts of esterified cholesterol (Henault and Killian, 1993c). The parallel findings of the studies of oviductal cholesterol synthesis in vitro and the lipid analysis of cannula-derived oviductal fluid appear to substantiate the validity of each of the approaches.

In contrast to cholesterol, phospholipids in the environment of the spermatozoa appear to destabilize the sperm membrane. In the present study, the concentrations of PS and LPS only were greater in isthmic oviductal fluid than in ampullary oviductal fluid when their mean concentrations were compared over all stages of the oestrous cycle. While cholesterol or phospholipid concentrations in the environment of the gamete may themselves affect sperm capacitation and the acrosome reaction, the cholesterol:phospholipid ratio may be more important to sperm membrane integrity. Langlais et al. (1988)
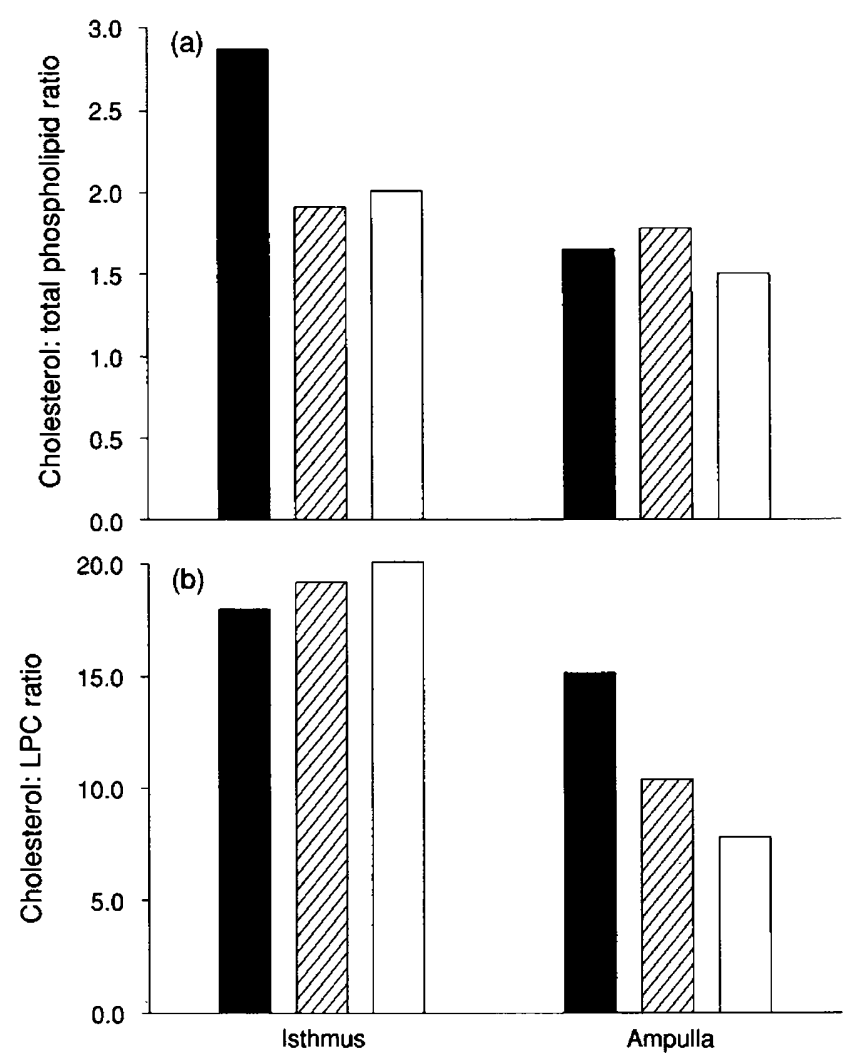

Fig. 3. Cholesterol:phospholipid ratios in bovine oviductal fluid $(n=4)$ collected from isthmus and ampulla during luteal $(\boldsymbol{\square})$, nonluteal $1(\square)$ and nonluteal $2(\square)$ stages of the oestrous cycle. Statistical analysis of these values was not performed. (a) Ratio of cholesterol $\left(\mu \mathrm{g} \mathrm{ml}^{-1}\right.$ ):phospholipid (percentage of total phospholipid). (b) Ratio of cholesterol ( $\mu \mathrm{g} \mathrm{ml}^{-1}$ ):lysophosphatidylcholine (percentage of total phospholipid).

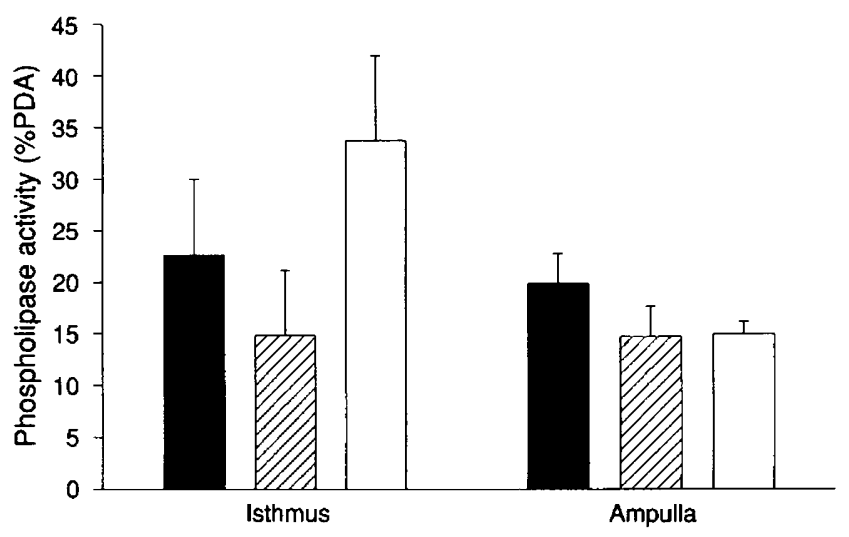

Fig. 4. Phospholipase activity [percentage amount of 6pyrenyldecanoic acid (PDA) produced] in bovine oviductal fluid $(n=5$; mean $\pm \mathrm{SD}$ ) collected from isthmus and ampulla during luteal (ם), nonluteal $I(\boxminus)$ and nonluteal $2(\square)$ stages of the oestrous cycle. Statistically significant differences are indicated in Table 1.

speculated that the inter-relationship of the spermatozoa with its surroundings may alter the sperm membrane cholesterol: phospholipid ratio, thus increasing the rate of capacitation when this ratio was low. In the study reported here, the highest 
cholesterol:phospholipid ratio was found in isthmic luteal fluid, while the lowest was in ampullary nonluteal 2 oviductal fluid. This supports the concept that the isthmus is a stabilizing environment for spermatozoa, and that the acrosome reaction is impeded in this region.

Oviductal fluid collected from the ampullary region generally had lower cholesterol concentrations and higher phospholipid amounts than that from the isthmic region, resulting in lower cholesterol:phospholipid ratios during all stages of the oestrous cycle. This implicates the ampulla as a destabilizing environment for spermatozoa that reside there, thus promoting the acrosome reaction.

Lower lipid concentrations in the gamete environment may promote the loss of cholesterol from the sperm membrane. Langlais and Roberts (1985) reported that such a cholesterol loss caused increased membrane fluidity and permeability, which may be important for capacitation and the acrosome reaction. In addition, cholesterol acceptors present in the fluid environment appear to facilitate cholesterol efflux from the spermatozoa of several species (Davis, 1981; Bearer and Friend, 1982; Go and Wolf, 1983). There are two cholesterol acceptors, albumin and high-density lipoprotein, in oviductal fluid (Ehrenwald et al., 1990; Gerena and Killian, 1990). Davis et al. (1979) studied the interaction between sperm membrane lipids and medium containing albumin. Studies with rat spermatozoa showed the efflux of cholesterol from the sperm membrane into the albumin, along with the influx of phospholipid to the sperm membrane. In the present study, we found that the lowest concentrations of cholesterol occurred in ampullary fluid that was collected during the nonluteal 2 stage, suggesting that the proper environment for sperm membrane destabilization is indeed at the site and time of availability of ova.

In contrast to cholesterol, phospholipids in the vicinity of spermatozoa appear to destabilize the sperm membrane. The mean amounts of PC, LPC and PE/LPE were higher in ampullary fluid than in isthmic fluid. The most significant differences were found with respect to the phospholipid LPC, which induces the acrosome reaction and which was at its highest concentration in ampullary oviductal fluid at the time of ovulation and fertilization. Exposure of bovine spermatozoa to LPC and LPE, among others, promotes the loss of acrosomal integrity (Wheeler and Seidel, 1989). Incubation of guinea-pig spermatozoa with PE and PI increases the frequency of the acrosome reaction (Fleming and Yanagimachi, 1981). Davis et al. (1979) found that PS was more easily transferred to rat spermatozoa from the medium than was LPC and PC, indicating the importance of the phospholipid content of the medium to membrane stability and capacitation.

The cholesterol:phospholipid ratio of the environment may be the most important indicator of possible effects on sperm membrane stabilization. In the present study, the lowest cholesterol:phospholipid ratio was in ampullary nonluteal 2 oviductal fluid, suggesting that the oviduct environment of the ampulla during the nonluteal 2 stage facilitates membrane destabilization and thus promotes sperm capacitation and the acrosome reaction.

Significant differences in stage were observed with SM, particularly in ampullary oviductal fluid. SM comprises approximately $15 \%$ of the phospholipids in the plasma membranes of ram spermatozoa (Hinkovska et al., 1986). This high concentration of SM may play a role in regulating membrane fluidity (Barenholz and Thompson, 1980) and thus membrane reactivity. Patton (1970) suggested that intracellular membrane ratios of cholesterol:total phospholipid may be correlated with SM content (Patton, 1970). We observed similar trends between this ratio and the concentration of SM in ampullary oviductal fluid, both of which were higher during the luteal than nonluteal phases.

Phospholipase activity has been implicated in the preparation of spermatozoa for fertilization. Hydrolysis of phospholipids by phospholipase $A_{2}$ in the presence of calcium produces lysophospholipid compounds that are potent in promoting the acrosome reaction (Fleming and Yanagimachi, 1984). In the present study, phospholipase activity was maximal in isthmic fluid at the time of ovulation and fertilization. However, the highest concentration of LPC was found in ampullary oviductal fluid during the nonluteal 2 stage of the oestrous cycle. Apparently, concentrations of LPC and other lysophospholipids in oviductal fluid do not parallel phospholipase activity in oviductal fluid. High phospholipase activity in isthmic oviductal fluid may be regulated by calcium; the role of calcium in promoting phospholipase $\mathrm{A}_{2}$ activity is well documented (Imai et al., 1990). Because the calcium concentration is highest in isthmic oviductal fluid collected during the nonluteal 2 stage (Grippo et al., 1992), phospholipase activity in this type of fluid may be enhanced. In addition, our observations do not account for the activity of membrane-bound phospholipase $A_{2}$ in spermatozoa and its effect on phospholipids in oviductal fluid and in the sperm membrane. Endogenous phospholipase $A_{2}$ may degrade PC in the plasma membrane, and subsequently promote the acrosome reaction (Fleming and Yanagimachi, 1984). Moreover, membrane-bound enzymes, such as phospholipase $A_{2}$, may change in distribution and configuration with the loss of cholesterol from the sperm membrane (Cullis et al., 1985). These changes may activate endogenous phospholipase $\mathrm{A}_{2}$, and promote the accumulation of intracellular LPC that would enhance the acrosome reaction.

Because the membrane lipid composition of spermatozoa can apparently vary with its environment, the molecular definition of oviductal fluid is crucial in understanding sperm capacitation and the acrosome reaction in the oviduct. In this study, we found differences in the concentrations of cholesterol and phospholipids, and phospholipase activity in bovine oviductal fluid collected from the isthmus and ampulla at different times of the oestrous cycle. The high ratio of cholesterol:total phospholipid in oviductal fluid collected from the isthmus (at all stages) would stabilize sperm plasma membranes, inhibiting the acrosome reaction. This finding supports the concept of the isthmus as the sperm reservoir. The lowest cholesterol: phospholipid ratio, which was found in ampullary fluid collected during the ovulatory phase, would destabilize sperm plasma membranes and promote capacitation and the acrosome reaction at the proper site and stage of the oestrous cycle for successful fertilization.

\section{References}

Barenholz Y and Tompson TE (1980) Sphingomyelin in bilayers and biomembranes Biochimica et Biophysica Acta 604 129-158

Bearer EL and Friend DS (1982) Modification of anionic lipid domains preceding membrane fusion in guinea pig sperm Journal of Cell Biology $92604-615$ 
Bleau G, VandenHeuvel WGA, Andersen OF and Gwatkin RBL (1975) Desmosterol sulphate of hamster spermatozoa, a potent inhibitor of capacitation in vitro joumal of Reproduction and Fertility 43 175-178

Consentino MJ and Ellis IC (1981) A rapid simple radiometric assay for phospholipase $A_{2}$ activity Prostaglandins 22 309-322

Cullis PR, Hope MJ, deKruijff B, Verkleij AJ and Tilcock CPS (1985) Structural properties and functional roles of phospholipids in biological membranes. In Phospholipids and Cellular Regulation pp 3-59 Ed. JF Kuo. CRC Press, Boca Raton.

Davis BK (1976) Inhibitory effects of synthetic phospholipid vesicles containing cholesteryl on the fertilizing ability of rabbit spermatozoa Proceedings of the Society of Experimental Biology and Medicine 152257

Davis BK (1981) Timing of fertilization in mammals: sperm cholesterol/ phospholipid ratio as a determinant of the capacitation interval Proceedings of the National Academy of Sciences USA 78 7560-7564

Davis BK, Byrne R and Hungund B (1979) Studies on the mechanism of capacitation II. Evidence for lipid transfer between plasma membrane of rat sperm and serum albumin during capacitation in vitro Biochimica et Biophysica Acta 558 257-266

Diaz-Fontdevila M and Bustos-Obregon E (1993) Cholesterol and polyunsaturated acid enriched diet: effect on kinetics of the acrosome reaction in rabbit spermatozoa Molecular Reproduction and Development 35 176-180

Ehrenwald E, Parks JE and Foote RH (1988) Cholesterol efflux from bovine sperm. I. Induction of the acrosome reaction with lysophosphatidylcholine after reducing sperm cholesterol Gamete Research 20 145-147

Ehrenwald E, Foote RH and Parks JE (1990) Bovine oviductal fluid components and their potential role in sperm cholesterol efflux Molecular Reproduction and Development 25 195-204

Evans RW and Setchell BP (1978) Association of exogenous phospholipids with spermatozoa Journal' of Reproduction and Fertility 53 357-362

Fayrer-Hosken RA, Brackett BG and Brown J (1987) Reversible inhibition of rabbit sperm fertilizing ability by cholesterol sulfate Biology of Reproduction $36878-883$

Fleming AD and Yanagimachi R (1981) Effects of various lipids on the acrosome reaction and fertilizing capacity of guinea pig spermatozoa with special reference to the possible involvement of lysophospholipids in the acrosome reaction Gamete Research 4 253-273

Fleming AD and Yanagimachi R (1984) Evidence suggesting the importance of fatty acids and the fatty acid moieties of sperm membrane phospholipids in the acrosome reaction of guinea pig spermatozoa Journal of Experimental Zoology 229 485-489

Folch J, Lees M and Sloane-Stanley GH (1957) A simple method for isolation and purification of total lipids from animal tissue Journal of Biological Chemistry 226 497-509

Gerena RL and Killian GJ (1990) Electrophoretic characterization of proteins in oviduct fluid of cows during the estrous cycle journal of Experimental Zoology $256113-120$

Go KI and Wolf DP (1983) The role of sterols in sperm capacitation Advances in Lipid Research 20 317-330

Graham JK and Foote RH (1987a) Dilauroylphosphatidylcholine liposome effects in the acrosome reaction and in vitro penetration of zona-free hamster eggs by bull sperm: I. A fertility assay for fresh semen Gamete Research 16 133-145

Graham JK and Foote RH (1987b) Dilauroylphosphatidylcholine liposome effects in the acrosome reaction and in vitro penetration of zona-free hamster eggs by bull sperm: II. A fertility assay for frozen-thawed semen Gamete Research $16 \quad 146-158$
Grippo AA, Chapman DA and Killian GJ (1989) An improved assay for phospholipase A2 activity in sperm Joumal of Andrology 1047

Grippo AA, Henault MA, Anderson SH and Killian GJ (1992) Cation concentrations in fluid from the oviduct ampulla and isthmus of cows during the estrous cycle Journal of Dairy Science 75 58-65

Henault MA and Killian GJ (1993a) Neutral lipid droplets in bovine oviductal epithelium and lipid composition of epithelial cell homogenates Journal of Dairy Science 76 691-700

Henault MA and Killian GJ (1993b) Synthesis and secretion of lipids by bovine oviduct mucosal explants Joumal of Reproduction and Fertility 98 431-438

Henault MA and Killian GJ (1993c) Composition and morphology of lipid droplets from oviduct epithelial cells Anatomical Record 237 466-474

Hinkovska VTZ, Dimitrov GP and Koumanov KS (1986) Phospholipid composition and phospholipid asymmetry of ram spermatozoa plasma membranes International Journal of Biochemistry 18 1115-1121

Hunter RHF and Wilmut I (1984) Sperm transport in the cow. Peri-ovulatory redistribution of viable cells within the oviduct Reproduction, Nutrition, Development 24 597-608

Imai A, lida K, Kazutoshi M, Matsuda T and Tamaya T (1990) Evidence for tight coupling of phospholipase activation and $\mathrm{Ca}^{2+}$ influx during acrosome reaction of golden hamster spermatozoa Comparative Biochemistry and Physiology Series B $95635-639$

Kavanaugh JF, Grippo AA and Killian GJ (1991) Cannulation of the bovine ampullary and isthmic oviduct Journal of Investigative Surgery 5 11-17

Killian GJ and Chapman DA (1980) Glycerylphosphorylcholine, sialic acid and protein in epithelial cells isolated from the rat caput epididymidis by elutriation. Biology of Reproduction 22 846-850

Killian GJ, Chapman DA, Kavanaugh JF, Deaver DR and Wiggin HB (1989) Changes in phospholipids, cholesterol and protein content of oviduct fluid of cows during the oestrous cycle Journal of Reproduction and Fertility 86 $419-426$

Langlais J and Roberts KD (1985) A molecular membrane model of sperm capacitation and the acrosome reaction of mammalian spermatozoa Gamete Research 12 183- 224

Langlais J, Kan FWK, Granger L, Raymond L, Bleau G and Roberts KD (1988) Identification of sterol acceptors that stimulate cholesterol efflux from human spermatozoa during in vitro capacitation Gamete Research 20 185-201

Lowry OH, Rosebrough NJ, Farr AL and Randall RJ (1951) Protein measurement with the Folin phenol reagent Joumal of Biological Chemistry 193 266-275

Ohzu E and Yanagimachi R (1982) Acceleration of acrosome reaction in hamster spermatozoa by lysolecithin Journal of Experimental Zoology 224 259-263

Patton S (1970) Correlative relationship of cholesterol and sphingomyelin in cell membranes Journal of Theoretical Biology 29 489-491

Singleton CLK and Killian GJ (1983) A study of phospholipase in albumin and its role in inducing the acrosome reaction of guinea pig spermatozoa in vitro Journal of Andrology 4 150-156

Statistical Analysis System (1985) SAS Users Guide. SAS Institute, Cary, NC.

Thakkar JK, East J and Franson RC (1984) Modulation of phospholipase A2 activity associated with human sperm membranes by divalent cation and calcium antagonists Biology of Reproduction 30 679-686

Thuren T, Virtanen JA, Lalla M and Kinnunen PKJ (1985) Fluorometric assay for phospholipase A2 in serum Clinical Chemistry 31 714-717

Wheeler MB and Seidel GE, Jr (1989) Capacitation of bovine spermatozoa by lysophospholipids and trypsin Gamete Research 22 193-204

Yanagimachi R and Suzuki F (1985) A further study of lysolecithin-mediated acrosome reaction of guinea pig spermatozoa Gamete Research 11 29-40 